\section{PEMBELAJARAN \\ PERCAKAPAN \\ BERBAHASA INGGRIS \\ UNTUK SISWA SEKOLAH \\ MELALUI SIARAN RADIO \\ KARYSMA FM PADA \\ PANDEMI COVID-19}

Arini Hidayah', Ika Oktaria

Cahyaningrum ${ }^{2}$, Yunita Widiyantari ${ }^{3}$,

Widyashanti K Anindhita ${ }^{4}$, Ramadhian

Agus Triono $\mathrm{S}^{5}$

\author{
1,2,3,4) Sastra Inggris, \\ Universitas Surakarta \\ 5) Teknik Informatika, \\ Universitas Surakarta \\ * Arini Hidayah \\ Email : ariniunsa@gmail.com
}

\begin{abstract}
Learning in the Covid-19 pandemic has changed offline learning become online learning. Online learning has several problems for teachers, students, and parents. The covid-19 pandemic in 2020 has had a significant impact in all fields, especially in the education field. Learning English daily conversation through Karysma FM Radio aims to teach students daily conversation and motivate students to deepen their understanding of English subjects outside of school time. The methodology applied in the implementation of community service is observation and the implementing teaching process. The conclusions of learning English daily conversation through Karysma FM Radio are I) Teaching English daily conversation with students at Karysma FM Radio requires creativity and English language skills; 2) Knowing the psychology of students, it is necessary to invite students to be willing to speak in English daily conversation considering that English subjects are lessons outside of school; 3) The obstacles in teaching English daily conversation with students at Radio Karysma FM are preparation of time and teaching materials.

Keywords: Covid-1 9 Pandemic, English Learning, and Conversation
\end{abstract}

\begin{abstract}
Abstrak
Pembelajaran pada pandemi Covid-19 telah mengubah pembelajaran tatap muka atau luring menjadi pembelajaran secara online atau daring. Pembelajaran daring terdapat beberapa kekurangan baik yang dirasakan oleh guru, siswa, dan orang tua. Pandemi Covid-19 yang terjadi pada tahun 2020 telah memberikan dampak yang sangat besar dalam semua bidang, khususnya pada bidang pendidikan. Pembelajaran Bahasa Inggis dalam kehidupan sehari-hari melalui Radio Karysma FM bertujuan mengajarkan siswa dalam percakapan Bahasa Inggris yang digunakan sehari-hari dan memberikan motivasi kepada siswa agar lebih mendalami mata pelajaran Bahasa Inggris di luar waktu pembelajaran sekolah. Metodologi yang diterapkan dalam pelaksanaan pengabdian kepada masyarakat ini adalah observasi dan proses pelaksanaan pengajaran. Kesimpulan pembelajaran Bahasa Inggis dalam kehidupan sehari-hari melalui Radio Karysma FM adalah I) Pengajaran percakapan Bahasa Inggris dalam kehidupan sehari-hari dengan siswa di Radio Karysma FM membutuhkan kreatifitas dan kemampuan berbahasa Inggris; 2) Dalam mengetahui psikologis siswa diperlukan dalam mengajak siswa agar bersedia berbicara dalam percakapan berbahasa Inggris dalam kehidupan sehari-hari mengingat mata pelajaran Bahasa Inggris merupakan pelajaran yang di luar sekolahan; 3) Hambatan dalam pengajaran percakapan Bahasa Inggris dalam kehidupan sehari-hari dengan siswa di Radio Karysma FM adalah persiapan waktu dan bahan ajar. Kata Kunci: Pandemi Covid-19, Pembelajaran, dan Percakapan Bahasa Inggris
\end{abstract}

Received: August 28, 202 I / Accepted: August 30, 202 I / Published Online: August 30, 202 I 
Pembelajaran Percakapan Berbahasa Inggris untuk Siswa Sekolah melalui Siaran Radio Karysma FM pada Pandemi Covid-19

Arini Hidayah, Ika Oktaria Cahyaningrum, Yunita Widiyantari, Widyashanti K Anindhita, Ramadhian Agus Triono S

Volume 1, No. 2, Agustus 2021 hal. 172-177

DOI Artikel : 10.46306/jub.v1i2.33

\section{PENDAHULUAN}

Pembelajaran pada pandemi Covid-19 (Kemdikbud: 2020) telah mengubah pembelajaran tatap muka atau luring menjadi pembelajaran secara online atau daring. Akan tetapi pembelajaran daring terdapat beberapa kekurangan baik yang dirasakan oleh guru atau pengajar, siswa atau pelajar, dan orang tua. Pandemi Covid-19 yang terjadi pada tahun 2020 telah memberikan dampak yang sangat besar dalam semua bidang, khususnya pada bidang pendidikan. Karena adanya pandemi Covid- 19 ini membuat proses pembelajaran berubah menjadi pembelajaran online atau daring atau jarak jauh, akan tetapi guru atau pengajar harus melakukan kewajibannya yang mana guru atau pengajar harus memastikan bahwa siswa atau pelajar agar bisa memperoleh informasi atau pengetahuan (Cahyaningrum dan Baraja: 202I). Pada bulan Maret 2020 Kementerian Pendidikan dan Kebudayaan (Kemdikbud: 2020) memberikan aturan kepada masyarakat bahwa pembelajaran online atau daring atau jarak jauh yang harus dilakukan oleh siswa atau pelajar belajar dari rumahnya sendiri-sendiri tanpa pergi ke sekolahnya. Ilmu tekhnologi sangat diperlukan bagi guru, siswa, dan orag tua dalam melakukan pembelajaran online pada pandemi Covid-19. Dalam pemanfaatan tekhnologi dalam pelaksanaan pembelajaran maka guru melakukan perubahan besar kepada siswa dalam pembelajaran online seperti Whatsapp, zoom, google meet, google classroom, dIl.

Kementerian Pendidikan dan Kebudayaan (Kemdikbud: 2020) memiliki program khusus yang dapat membantu masyarakat yang memiliki keterbatasan pada akses internet, secara ekonomi maupun lokasi atau jarak rumah dengan cara belajar melalui media massa seperti televisi atau radio yang ditujukan kepada para siswa dari tingkat Taman Kanak-Kanak atau Pendidikan Anak Usia Dini sampai tingkat Sekolah Menengah Atas atau Sekolah Menengah Kejuruan yakni dalam upaya terselenggaranya pendidikan untuk semua pihak dimasa pandemik Covid-19.

Mata Pelajaran Bahasa Inggris merupakan salah satu pelajaran wajib muatan Nasional yang diajarkan pada sekolah Indonesia (Sutardi: 20I I). Mata Pelajaran Bahasa Inggris diajarkan kepada siswa atau pelajar dalam waktu 90 menit perminggu dalam satu minggu. Waktu pembelajaran mata pelajaran Bahasa Inggris sangat terbatas dalam mempelajari kemampuan Bahasa Inggris. Keterbatasan waktu yang diajarkan di sekolahan menjadikan para siswa tidak bisa mempraktekkan ilmu Bahasa Inggris yang dipelajari, apalagi dalam pembelajaran jarak jauh di masa pandemi Covid-19 saat ini, membuat siswa atau pelajar tidak dapat mengaplikasikan ilmu yang dipelajari yang didapat secara fleksibel. Pihak orang tua siswa atau pelajar yang mempunyai ekonomi yang menegah ke atas dapat mengarahkan anaknya agar mengikuti les Bahasa Inggris di luar pelajaran sekolah. Sedangkan orang tua siswa atau pelajar yang berasal dari ekonomi menengah ke bawah akan mengalami kesulitan karena orang tua siswa atau pelajar menganggap bahwa les Bahasa Inggris untuk anak adalah kebutuhan yang biasa saja yang dapat ditunda karena masih banyak kepentingan lain yang bisa menjadi lebih prioritas keluarga.

Berdasarkan informasi yang diperoleh langsung dari pihak siswa, orang tua, dan guru yang mengalami kendala dalam pembelajaran mata pelajaran Bahasa Inggris pada masa pandemi Covid-19. Oleh karena itu 
Pembelajaran Percakapan Berbahasa Inggris untuk Siswa Sekolah melalui Siaran Radio Karysma FM pada Pandemi Covid-19

Arini Hidayah, Ika Oktaria Cahyaningrum, Yunita Widiyantari, Widyashanti K Anindhita, Ramadhian Agus Triono S

Volume 1, No. 2, Agustus 2021 hal. 172-177

DOI Artikel : 10.46306/jub.v1i2.33

penulis mencoba melakukan pengabdian kepada masyarakat dalam pembelajaran Bahasa Inggis dalam kehidupan sehari-hari melalui media massa yakni Radio Karysma FM dengan judul Pembelajaran Percakapan Berbahasa Inggris Untuk Siswa Pada Pandemi Covid-19. Pembelajaran Bahasa Inggis dalam kehidupan sehari-hari melalui Radio Karysma FM bertujuan mengajarkan siswa dalam percakapan Bahasa Inggris yang digunakan sehari-hari dan memberikan motivasi kepada siswa agar lebih mendalami mata pelajaran Bahasa Inggris di luar waktu pembelajaran sekolah.

\section{METODE PENGABDIAN}

Metodologi yang diterapkan dalam pelaksanaan pengabdian kepada masyarakat dalam pembelajaran Bahasa Inggris dalam kehidupan sehari-hari melalui Radio Karysma Fm adalah sebagai berikut:

\section{Observasi}

Tujuan metode observasi (Ristekdikti: 2018) yakni untuk mendapatkan gambaran atau latar belakang masalah yang tepat yang berhubungan dengan kondisi dan lokasi tempat dalam proses pengabdian kepada masyarakat berlangsung. Tim pengabdian kepada masyarakat memerlukan waktu

dalam proses pengamatan gambaran masalah, kondisi, lokasi tempat perencanaan, dan perencanaan pembelajaran dalam pengabdian kepada masyarakat selama 2 jam.

\section{Proses Pelaksanaan Pengajaran}

Pelaksanaan pembelajaran mata pelajaran Bahasa Inggris kepada siswa di Radio Karysma FM dilakukan dalam sekali pertemuan dengan memakan waktu I jam yang dilakukan oleh penulis pengabdian kepada masyarakat. Langkah pertama dalam pembelajaran mata pelajaran Bahasa Inggris kepada siswa di Radio Karysma FM yakni tim pengabdian kepada masyarakat mengajarkan siswa tentang percakapan berbahasa Inggris yang digunakan sehari-hari. Langkah kedua mengajak para pendengar terutama pendengar yang masih pelajar berinteraksi langsung dengan tim pengabdian kepada masyarakat melalui telfon interaktif dengan mengajak siswa mempraktekkan langsung percakapan berbahasa Inggris yang digunakan seharihari yang telah dipelajari di tahap pertama. Bahan materi pelajaran Bahasa Inggris yang digunakan untuk bahan pengajaran percakapan Bahasa Inggris dalam pengabdian kepada masyarakat berupa dialog atau percakapan sehari-hari seperti salam atau sapaan, tanya jawab mengenai informasi pengenalan diri sendiri atau orang lain. Dalam pengajaran mata pelajaran Bahasa Inggris kepada siswa, tim pengabdian kepada masyarakat menggunakan fungsi berbahasa Inggris untuk keperluan berkomunikasi dengan menggunakan latihan berpasangan antara tim pengabdian kepada masyarakat dengan siswa (Tsani, Aniuranti, \& Budiman: 202I). Topik Daily English Conversation (Lou: 20II) yang digunakan dalam materi ajar yang digunakan antara lain: I) What's Your Name?, 2) Who Are You?, 3) How Are You?, 4) What is your hobby?, 5) What do you do?, 6) Where will you go?, 7) Where do you want to go?, 8) Can you help me?. 
Pembelajaran Percakapan Berbahasa Inggris untuk Siswa Sekolah melalui Siaran Radio Karysma FM pada Pandemi Covid-19

Arini Hidayah, Ika Oktaria Cahyaningrum, Yunita Widiyantari, Widyashanti K Anindhita, Ramadhian Agus Triono S

Volume 1, No. 2, Agustus 2021 hal. 172-177

DOI Artikel : 10.46306/jub.v1i2.33

\section{PELAKSANAAN DAN PEMBAHASAN}

Program pengabdian kepada masyarakat melalui pengajaran percakapan Bahasa Inggris dalam kehidupan sehari-hari yang dilakukan di Radio Karysma FM yang dilaksanakan pada tanggal 28 Desember 2020 pada pukul 4 sampai 5 sore. Terdapat 7 siswa yang mengikuti pembelajaran percakan berbahasa Inggris yang digunakan sehari-hari melalui telfon interaktif. Para siswa yang mengikuti pembelajaran percakan berbahasa Inggris umumnya tinggal di Boyolali.

Evalusi keberhasilan program pengabdian kepada masyarakat dalam pengajaran percakapan Bahasa Inggris dalam kehidupan sehari-hari yang dilakukan di Radio Karysma FM dapat dapat diambil dari evaluasi yang dilakukan. Evaluasi keberhasilan pengajaran percakapan Bahasa Inggris dalam kehidupan sehari-hari yang dilakukan di Radio Karysma FM antara lain: I) Siswa dapat mengetahui pelajaran atau materi yang telah diajarkan, 2) Terdapat ada kesinambungan atau hubungan antara materi ajar pengajaran percakapan Bahasa Inggris dalam kehidupan sehari-hari dan kebutuhan siswa dalam mata pelajaran Bahasa Inggris, 3) Penggunaan metode pembelajaran dalam materi ajar percakapan Bahasa Inggris dalam kehidupan sehari-hari dengan siswa telah sesuai kondisi, 4) Siswa diberikan ujian oleh tim pengabdian kepada masyarakat untuk mengetahui perkembangan kemampuan percakapan Bahasa Inggris dalam kehidupan sehari-hari.

Selama proses pengajaran percakapan Bahasa Inggris dalam kehidupan sehari-hari dengan siswa di Radio Karysma FM, para siswa tampak semangat dan termotivasi dalam menjawab pertanyaan dari tim pengabdian kepada masyarakat. Siswa dapat mengetahui dan menyerap kosakata yang baru agar dapat membuat percakapan yang bagus.

Situasi dan kondisi tersebut memberikan indikator kesuksesan dalam proses pengajaran percakapan Bahasa Inggris dalam kehidupan sehari-hari dengan siswa di Radio Karysma FM karena siswa dapat mengaplikasikan percakapan Bahasa Inggris dalam kehidupan sehari-hari serta materi ajar sudah sesuai dengan yang dibutuhkan siswa. Sehingga siswa dapat memahami materi ajar dan dapat menjawab ujian percakapan berbahasa Inggris dengan baik

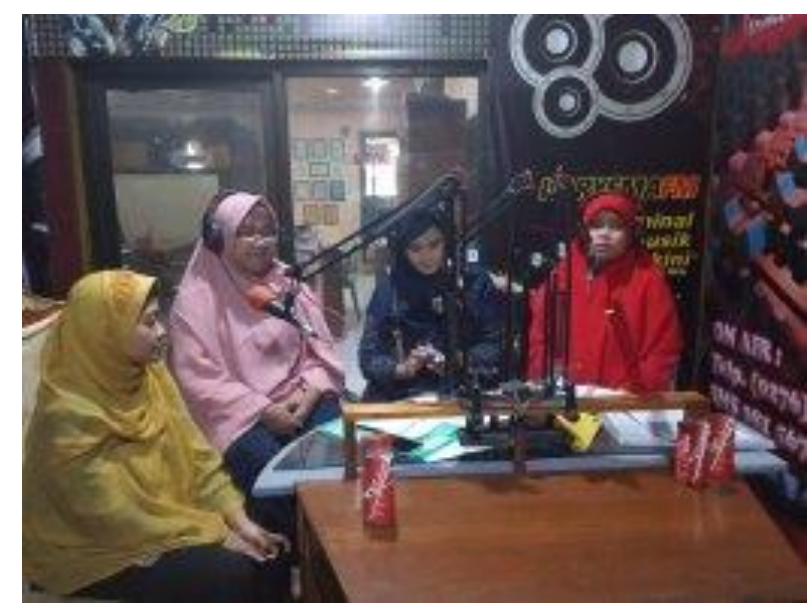


Pembelajaran Percakapan Berbahasa Inggris untuk Siswa Sekolah melalui Siaran Radio Karysma FM pada Pandemi Covid-19

Arini Hidayah, Ika Oktaria Cahyaningrum, Yunita Widiyantari, Widyashanti K Anindhita, Ramadhian Agus Triono S

Volume 1, No. 2, Agustus 2021 hal. 172-177

DOI Artikel : 10.46306/jub.v1i2.33

Gambar I: Pembukaan Kegiatan Pembelajaran Percakapan Berbahasa Inggris Untuk Siswa Pada Pandemi Covid-19 Di Radio Karysma FM.

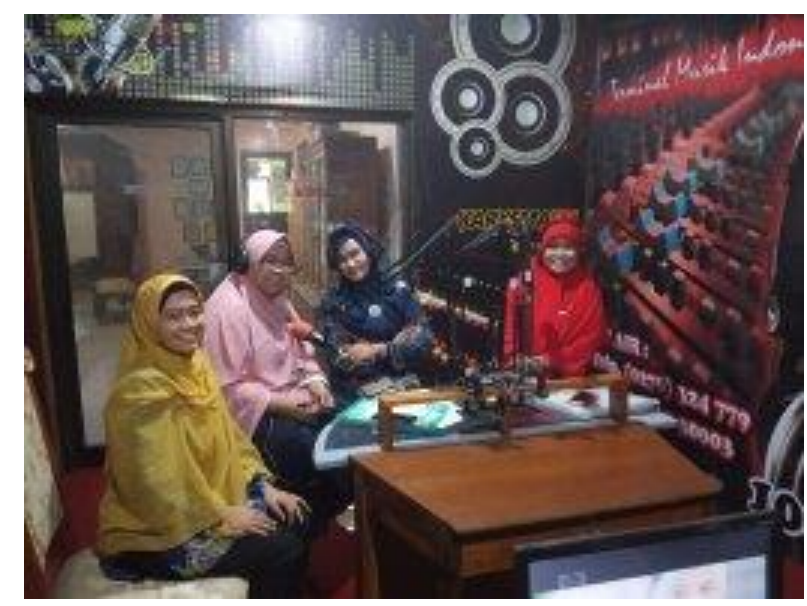

Gambar 2: Penutupan Kegiatan Pembelajaran Percakapan Berbahasa Inggris Untuk Siswa Pada Pandemi Covid-19 Di Radio Karysma FM.

\section{KESIMPULAN DAN SARAN}

Kegiatan pengabdian kepada masyarakat yang berupa kegiatan pengajaran percakapan Bahasa Inggris dalam kehidupan sehari-hari dengan siswa di Radio Karysma FM dapat disimpulkan bahwa: I) Pengajaran percakapan Bahasa Inggris dalam kehidupan sehari-hari dengan siswa di Radio Karysma FM membutuhkan kreatifitas dan kemampuan berbahasa Inggris. Penulis berusaha mengajak siswa agar tertarik dalam praktik pengajaran dalam percakapan Bahasa Inggris dalam kehidupan sehari-hari agar tujuan tercapai, 2) Dalam mengetahui psikologis siswa diperlukan dalam mengajak siswa agar bersedia berbicara dalam percakapan berbahasa Inggris dalam kehidupan sehari-hari mengingat mata pelajaran Bahasa Inggris merupakan pelajaran yang di luar sekolahan, 3) Hambatan dalam pengajaran percakapan Bahasa Inggris dalam kehidupan sehari-hari dengan siswa di Radio Karysma FM adalah persiapan waktu dan bahan ajar. Tim pengabdian kepada masyarakat harus membuat waktu yang sesuai dengan jadwal siswa pada waktu yang dimungkinkan setelah waktu sekolah selesai agar waktu dalam proses pengabdian kepada masyarkat tepat dalam memberikan pelajaran kepada siswa. Matari ajar yang diberikan ke siswa harus sesuai dengan tujuan program pengabdian kepada masyarakat.

Dengan diadakan pengajaran ini, diharapkan siswa dapat memiliki tambahan ilmu pengetahuan dalam percakapan Bahasa Inggris dalam kehidupan sehari-hari sehingga siswa mendapatkan kesenangan dalam memperkaya ilmu tanpa merasa kesulitan dalam menyerap pelajaran yang telah disampaikan. 
Pembelajaran Percakapan Berbahasa Inggris untuk Siswa Sekolah melalui Siaran Radio Karysma FM pada Pandemi Covid-19

Arini Hidayah, Ika Oktaria Cahyaningrum, Yunita Widiyantari, Widyashanti K Anindhita, Ramadhian Agus Triono S

Volume 1, No. 2, Agustus 2021 hal. 172-177

DOI Artikel : 10.46306/jub.v1i2.33

\section{UCAPAN TERIMA KASIH}

Kami mengucapkan terima kasih kepada Radio Karysma FM yang telah memberikan dukungan sebagai tempat kami dalam melaksanakan kegiatan pengabdian kepada masyarakat. Terima kasih kepada LP2M Universitas Surakarta yang telah memberikan izin kepada kami sehingga dapat melaksanakan kegiatan pengabdian kepada masyarakat dengan lancar. Terima kasih kepada Program Studi Sastra Inggris Fakultas Bahasa dan Sastra yang telah mensuport dalam pelaksanaan pengabdian kepada masyarakat.

\section{DAFTAR PUSTAKA}

Cahyaningrum, Ika, Oktaria \& Baraja, Abdillah. (202I). Workshop Pengembangan Media Pembelajaran Dan Bahasa Inggris Berbasis Teknologi Informatika Di Era Pandemi Bagi Guru Sdit Al Falaah Simo. Jubaedah : Jurnal Pengabdian dan Edukasi Sekolah, Volume I, No. I, April 202I hal. 37-43.

Direktorat Riset dan Pengabdian Masyarakat Direktorat Jenderal Penguatan Riset dan Pengembangan Kementerian Riset, Teknologi, dan Pendidikan Tinggi. (2018). Panduan Penilaian Kinerja Pengabdian Kepada Masyarakat Di Perguruan Tinggi. Jakarta: Direktorat Riset dan Pengabdian Masyarakat, Direktorat Jenderal Penguatan Riset dan Pengembangan Kementerian Riset, Teknologi, dan Pendidikan Tinggi.

Kementerian Pendidikan dan Kebudayaan. (2020). "Panduan Penyelenggaraan Pembelajaran pada Tahun Ajaran dan Tahun Akademik Baru di Masa Covid-19". Diakses pada https://www.kemdikbud.go.id/main/blog/2020/06/panduan-penyelenggaraan-pembelajaranpada-tahun-ajaran-dan-tahun-akademik-baru-di-masa-covid 9.

Kementerian Pendidikan dan Kebudayaan. (2020). "Kemendikbud Terbitkan Pedoman Penyelenggaraan Belajar dari Rumah". Diakses pada https://www.kemdikbud.go.id/main/blog/2020/05/kemendikbud-terbitkan-pedomanpenyelenggaraan-belajar-dari-rumah.

Kementerian Pendidikan dan Kebudayaan. (2020). "Kemendikbud Resmikan Kebijakan Bantuan Kuota Data Internet". Diakses pada https://www.kemdikbud.go.id/main/blog/2020/09/kemendikbud-resmikan-kebijakan-bantuankuota-data-internet-2020.

Lou, R. (20II). The Pocket Handbook of Daily Conversation And Dictionary Of Basic English. Jakarta: Mobile English Plus.

Sutardi, A. (20I I). Pengembangan Kurikulum Bahasa Inggris Berbasis Teknologi Informasi dan Komunikasi (TIK) SD Tulangampiang, Denpasar, Bali dan Implemntasinya. Jurnal Pendidikan dan Kebudayaan, Vol. I7, Nomor I, Januari 201 I.

Tsani, M, H, N, Aniuranti, A, Budiman, A. (202I). Pelatihan English Conversation Bagi Tenaga Pendidik Di Universitas Nahdlatul Ulama Purwokerto. Jubaedah : Jurnal Pengabdian dan Edukasi Sekolah, Volume. I, No. 2, Agustus 202I hal. I56-164. 